\title{
BIOTECNOLOGIA CONVERTENDO BAGAÇO DE MALTE EM NUTRIENTES PARA PRODUÇÃO DE COGUMELOS
}

\section{ARTIGO ORIGINAL}

SILVA, Rodrigo Santos da ${ }^{1}$

VÍTOLA, Francisco Menino Destéfanis²

SILVA, Michelli Aparecida Bertolazo $\mathrm{Da}^{3}$

SILVA, Rodrigo Santos da. VÍTOLA, Francisco Menino Destéfanis. SILVA, Michelli Aparecida Bertolazo Da. Biotecnologia convertendo bagaço de malte em nutrientes para produção de cogumelos. Revista Científica Multidisciplinar Núcleo do Conhecimento. Ano 04, Ed. 07, Vol. 11, pp. 79-100. Julho de 2019. ISSN: 24480959

\section{RESUMO}

Trata-se da produção de cogumelos com resíduo proveniente da cerveja. Com intuito de contribuir para sustentabilidade do planeta foi realizado um estudo que se objetivou em converter o bagaço de malte, resíduo produzido pelas cervejarias, em nutrientes para produção de cogumelos. Os cogumelos são seres pertencentes ao reino Fungi

${ }^{1}$ Acadêmico do Curso Superior em Biotecnologia da Universidade Tuiuti do Paraná (Curitiba, PR); Técnico em Gestão e Produção de Alimentos.

2 Graduado em Engenharia de Bio processos e Biotecnologia pela Universidade Federal do Paraná. Mestre pelo programa Master BIODEV da Universidade de Provence (França) e UFPR. Doutorado em Engenharia de Bio processos e Biotecnologia pela UFPR.

${ }^{3}$ Graduada em Farmácia pela Universidade Federal do Paraná. Possui mestrado no programa Ciências Farmacêuticas, pela Universidade Federal do Paraná e especialização em Citologia Clínica pela Sociedade Brasileira de Citologia Clínica e Conselho Regional de Farmácia. 
com grande potencial para humanidade, pois podem ser utilizados em diversas aplicações. Criou-se um meio de cultivo para produção de cogumelos com a adição do bagaço de malte, que foi comparado com um meio convencional e com bagaço de malte puro, avaliando o crescimento micelial dos fungos: Pleurotus ostreatus e Pleurotus sajor-caju Singer. Com base nesse estudo observou-se um equilíbrio no meio de cultura com de cultura com adição de bagaço de malte, pois o mesmo apresentou tanto um bom crescimento quanto um vigor intermediário entre os meios comparados. Comparou-se também a eficiência biológica da produção do cogumelo Pleurotus Sajor-caju Singer com o meio de cultivo com adição de bagaço de malte e com o meio convencional utilizando o cultivo axênico. Diante dos resultados de eficiência biológica novamente o meio de cultura com adição de bagaço de malte surpreendeu ao apresentar um valor de eficiência biológica um pouco maior que o do meio convencional. Através dessas comparações foi possível concluir que o bagaço de malte pode ser utilizado para produção de cogumelos e que é muito promissor, podendo fornecer mais resultados interessantes dependo da espécie a ser cultivada, ambiente ou variações em sua composição.

Palavras-chave: Cogumelo, eficiência biológica, sustentabilidade, bagaço do malte, resíduo da cerveja.

\section{INTRODUÇÃO}

Segundo dados do IBGE - (Instituto Brasileiro de Geografia e Estatística), o Brasil, em 2016, produziu 366.110 mil toneladas de grãos de cevada, cuja principal destinação foi o mercado cervejeiro para utilização em forma de malte. De uma maneira mais ampla, segundo Mussato et al. (2006), são gerados aproximadamente 30 milhões de toneladas de resíduos pelas cervejarias do mundo, e uma grande preocupação mundial é a destinação de resíduos, pois o descarte em local inadequado pode causar uma séria agressão ao meio ambiente.

A possibilidade da destinação de resíduos da indústria cervejeira para a produção de cogumelos é algo que pode vir a contribuir não só para sustentabilidade do planeta, quanto para a popularização e crescimento do mercado no país, pois o consumo 
brasileiro é considerado pequeno. Alguns fatores que ajudam a justificar o baixo consumo de cogumelos no Brasil são a baixa produção e elevado custo. Além disso, os cogumelos não fazem parte da dieta e nem da cultura brasileira. Estima-se que o consumo per capita brasileiro seja de aproximadamente 30 gramas de cogumelo ao ano, algo bem abaixo dos dois quilos consumidos pelos franceses e dos oito quilos consumidos por chineses no mesmo período (ERENO, 2008).

Muitos pesquisadores apresentaram estudos com relação à utilização resíduos para a produção de cogumelos como: GOMES, 2016, CARDOSO, 2013 e MONAICO, 2003 que utilizaram o bagaço da cana de açúcar ou FAN; SOCCOL, 2001 que utilizaram a casca e borra de café para essa finalidade.

A intenção desse trabalho é de contribuir com o desenvolvimento de uma alternativa para a destinação de resíduos orgânicos de cervejarias que podem ser revertidos em nutrientes para produção de cogumelos, beneficiando assim as duas áreas produtivas, além de contribuir e incentivar a popularização e consumo dos cogumelos. Para o experimento foram escolhidos os fungos Pleurotus sajor-caju Singer (Cogumelo Ostra Marrom) e Pleurotus ostreatus (Jaquin ex Fr,) Kummer (Shimeji Branco), ambos da família Pleurotaceae e da classe Hymenomycetes. Para tanto, foi elaborado um meio de cultura com adição de bagaço de malte, o qual foi comparado com um meio de cultura convencional além do bagaço de malte puro também como substrato, onde se avaliou o crescimento micelial in vitro dos fungos P.sajor-caju Singer e P.ostreatus todos misturados a ágar-ágar. Para testar a eficiência da produção de cogumelos, avaliou-se a eficiência biológica dos substratos: Convencional e com adição de bagaço de malte inoculados pelo fungo P.sajor-caju Singer.

\section{MATERIAL E MÉTODOS}

Para realização dos testes de eficiência biológica (EB) utilizou-se o cultivo axênico estimulando crescimento sem competição. 


\subsection{MATÉRIA PRIMA}

Para realização do experimento, foram utilizadas as seguintes matérias primas (QUADRO 1). O material foi gentilmente cedido pela empresa COGUBRAS e o bagaço de malte gentilmente cedido pela CERVEJARIA BODEBROWN.

Quadro 1: Matérias primas utilizadas

Cepilho ou serragem

Farelo de trigo

Calcário

Gesso

Sacos de polipropileno

Elásticos

Espuma de estofador

Sementes (Spawn, inoculo): Pleurotus Sajor-caju Singer - Cogumelo Ostra Marrom

e Pleurotus Ostreatus Jaquin ex Fr, Kummer - Shimeji Branco

Fonte: O autor

\subsection{EQUIPAMENTOS}

Os equipamentos utilizados foram: tambor plástico de 50 litros, peneira de diâmetro: $55 \mathrm{~cm}$ e malha: 05, Autoclave Vertical - (PHOENIX), caixa plástica de $78 \times 56 \times 41 \mathrm{~cm}$ (Largura $\times$ Comprimento $\times$ Altura), balança analítica Marte, Capela de fluxo laminar (TROX TECHNIK), Bico de Bunsen, Estufa B.O.D - Q-315F (QUIMIS).

\subsection{PREPARO DO MEIO DE CULTIVO}

O preparo dos meios de cultivo com bagaço de malte e convencional foram realizados de acordo com os quadros 2 e 3 . 
Quadro 2: Composição de meio de cultura convencional

\begin{tabular}{|l|l|}
\hline MEIO CONVENCIONAL & $\%$ \\
\hline ÁGUA & 65,8 \\
\hline CEPILHO & $28,2 \%$ \\
\hline FARELO DE TRIGO & $5,6 \%$ \\
\hline CALCÁRIO & $0,2 \%$ \\
\hline GESSO & $0,2 \%$ \\
\hline TOTAL & $100 \%$ \\
\hline
\end{tabular}

Fonte: O autor

Quadro 3: Composição de meio de cultura alternativo com adição de bagaço de malte

\begin{tabular}{|l|l|}
\hline MEIO COM BAGAÇO DE MALTE & $\%$ \\
\hline ÁGUA & 65,8 \\
\hline BAGAÇO DE MALTE & $22,2 \%$ \\
\hline CEPILHO & $6,9 \%$ \\
\hline FARELO DE TRIGO & $4,1 \%$ \\
\hline CALCÁRIO & $0,2 \%$ \\
\hline GESSO & $0,2 \%$ \\
\hline TOTAL & $100 \%$ \\
\hline
\end{tabular}

Fonte: O autor

As etapas foram realizadas na mesma ordem em que as imagens fluxograma 1 e 2 . 
Fluxograma 1: Cultivo In Vitro fluxograma

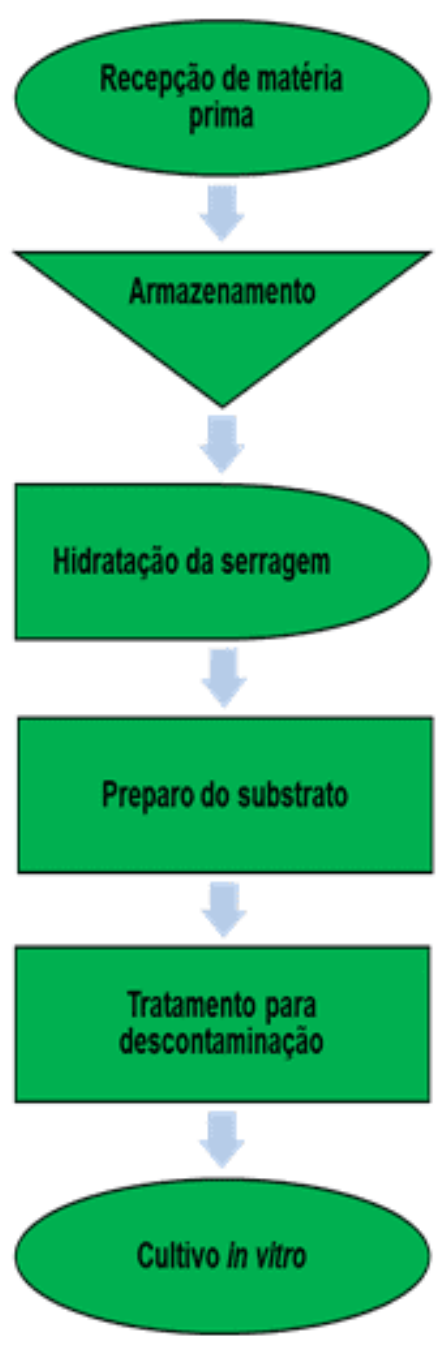

Fonte: O autor. 
Fluxograma 2: Cultivo Axênico

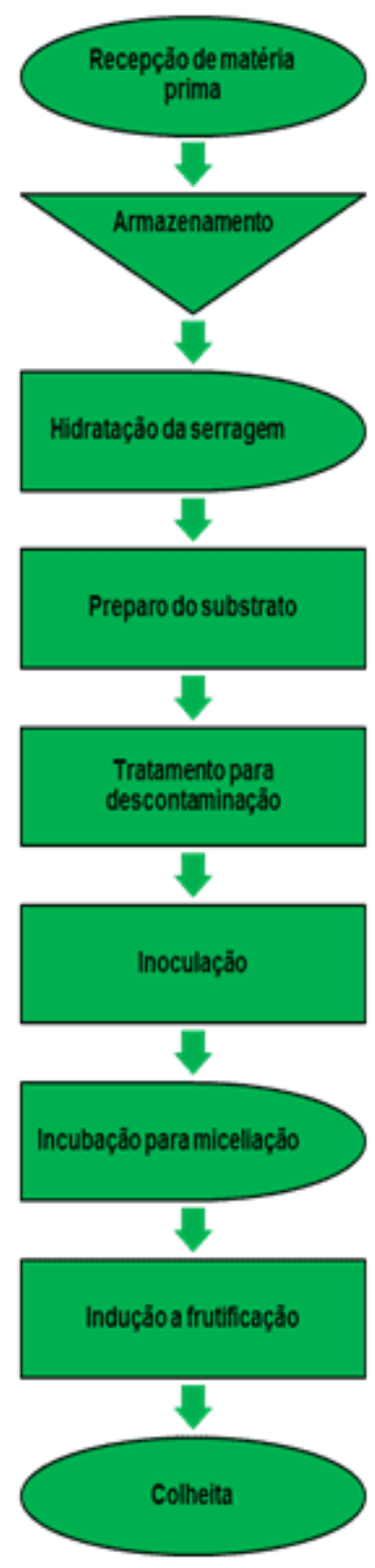

Fonte: $\mathrm{O}$ autor. 


\subsection{DESCRIÇÃO DAS ETAPAS DO PREPARO DOS MEIOS DE CULTIVO}

RECEPÇÃO DE MATÉRIA PRIMA: Foram avaliados lote e condições de recebimento das matérias prima como situação da embalagem para avaliarmos se existia a possibilidade de contaminação das sementes ou não.

ARMAZENAMENTO: A matéria prima recebida foi armazenada em local adequado, livre de luz e calor para que a mesma não sofresse alterações.

HIDRATAÇÃO DA SERRAGEM: Com auxílio do tambor plástico a serragem foi imersa em água por um período de 12 horas.

PREPARO DO SUBSTRATO: Tanto para o meio de cultivo convencional quanto para o meio de cultivo com bagaço de malte o processo de mistura foi o mesmo, realizado em caixa plástica nas proporções apresentadas nos quadros 2 e 3 .

Após realização da mistura, $300 \mathrm{~g}$ de meio de cultivo humido foram ensacados utilizando espuma de estofador e elásticos para fechar os sacos de polipropileno, criando um filtro como o representado na (FIGURA 1). 
Figura 1: Filtro de Espuma

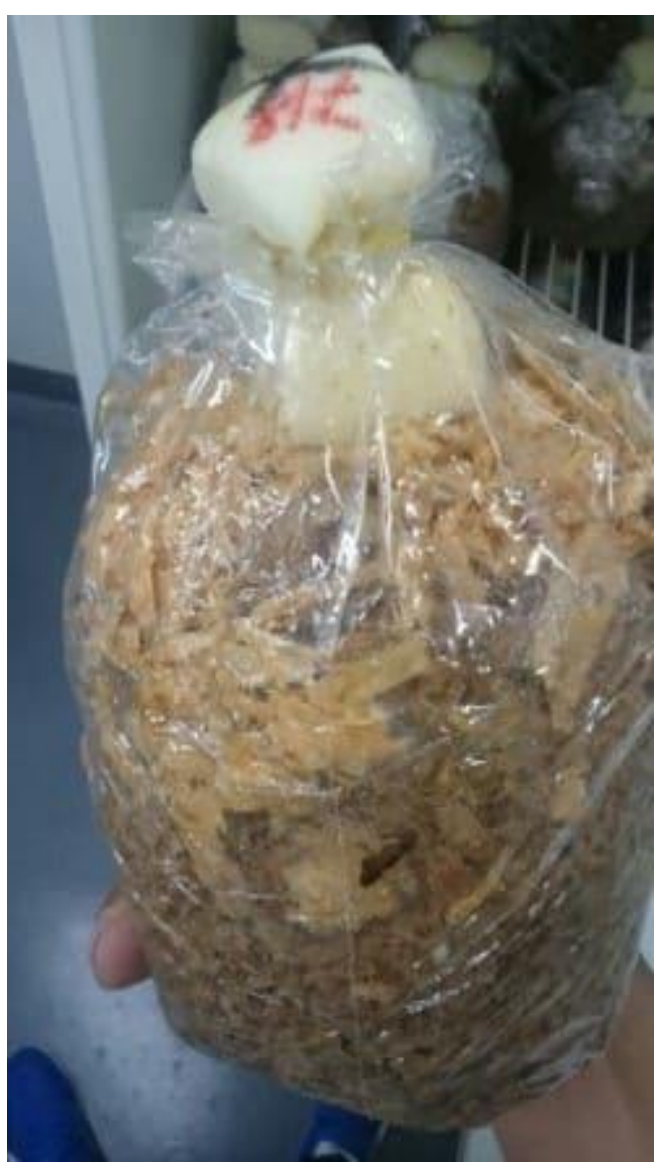

Fonte: O autor.

Seguindo esse formato, foram preparadas 20 amostras com o meio de cultivo convencional e 20 amostras com o meio de cultivo com bagaço de malte.

TRATAMENTO PARA DESCONTAMINAÇÃO: Os meios de cultivo ensacados foram autoclavados a uma temperatura de $120^{\circ} \mathrm{C}$ por 40 minutos. Os meios de cultivo autoclavados foram utilizados tanto no cultivo axênico quanto no cultivo in vitro.

CULTIVO IN VITRO: Placas de Petri foram preenchidas com os meios de cultivo utilizados no cultivo axênico que são: 1- Meio convencional, 2- Meio com adição de bagaço de malte além de 3- bagaço de malte puro, seguido pela adição de agar-agar sobre cada placa. Foram adicionadas ao centro de cada placa a semente dos fungos P.Sajor-caju Singer e P.Ostreatus, fechadas as placas com papel filme transparente 
(FIGURA 2) e incubadas em estufa a $25^{\circ} \mathrm{C}$, realizando a medição do crescimento micelial dos fungos diariamente após o terceiro dia de incubação. $O$ experimento foi dividido em 6 grupos (QUADRO 4).

Quadro 4: Placas relacionadas a cada meio e espécie

\begin{tabular}{|l|l|}
\hline MEIO+ESPÉCIE CULTIVADA & $\begin{array}{l}\text { QUANTIDADE } \\
\text { PLACAS }\end{array}$ \\
\hline P.sajor-caju em Meio convencional & 3 \\
\hline P.ostreatus em Meio convencional & 2 \\
\hline P.sajor-caju em Meio com adição de bagaço de malte & 2 \\
\hline P.ostreatus em Meio com adição de bagaço de malte & 2 \\
\hline P.sajor-caju em Bagaço puro de malte & 2 \\
\hline P.ostreatus em Bagaço puro de malte & 3 \\
\hline
\end{tabular}

Fonte: O autor 


\section{MULTIDISCIPLINARY SCIENTIFIC JOURNAL

Figura 2: Medição de crescimento micelial
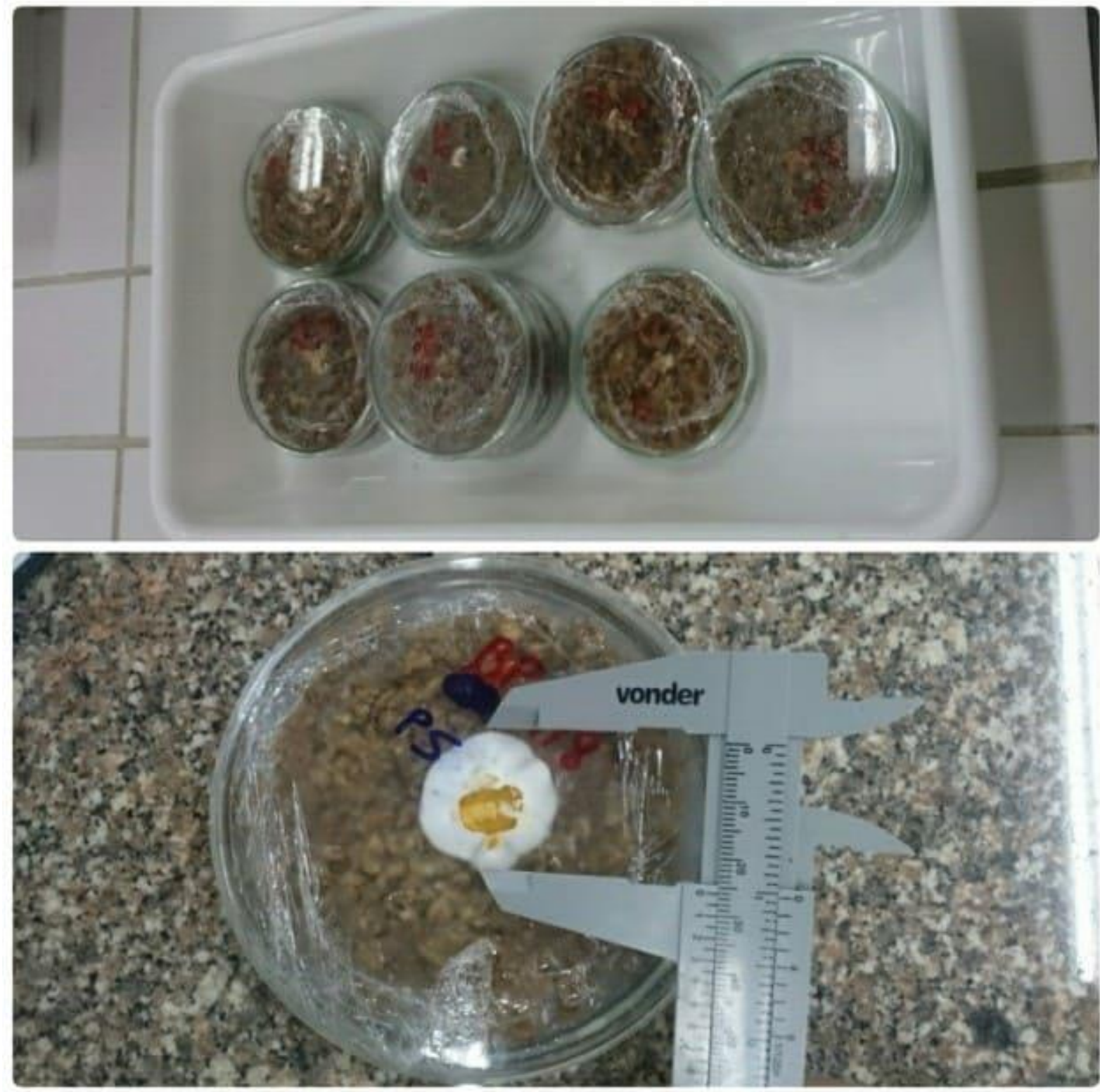

Fonte: O autor

INOCULAÇÃO DOS SACOS DO CULTIVO AXÊNICO: Com auxílio da capela de fluxo laminar e do bico de bunsen $15 \mathrm{~g}$ de semente - Spawn foram inoculados em cada amostra estéril, como representado no quadro 5 : 
Quadro 5: Amostras em incubação

\begin{tabular}{|l|l|}
\hline MEIO+ESPÉCIE CULTIVADA & $\begin{array}{l}\text { QUANTIDADE } \\
\text { AMOSTRAS }\end{array}$ \\
\hline $\begin{array}{l}\text { P.sajor-caju em Meio convencional } \\
\text { P.sajor-caju em Meio com adição de bagaço de } \\
\text { malte }\end{array}$ & 10 \\
\hline
\end{tabular}

Fonte: $\mathrm{O}$ autor

INCUBAÇÃO PARA MICELIAÇÃO: Todos os sacos com meio de cultivo ficaram incubados no equipamento B.O.D Q-315F (QUIMIS) por 30 dias (FIGURA 3).

Figura 3: Amostras em incubação

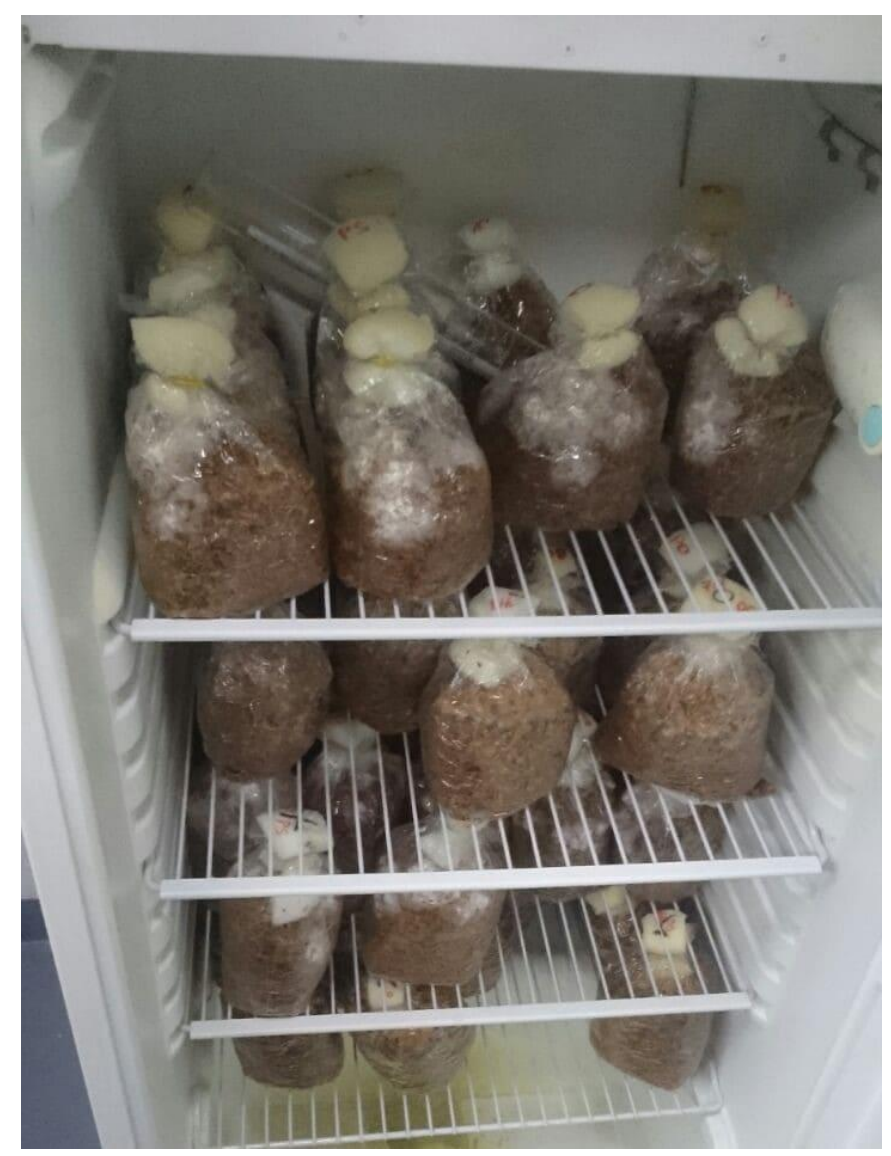

Fonte: $\mathrm{O}$ autor. 
INDUÇÃO A FRUTIFICAÇÃO: Foram feitos pequenos cortes nos sacos em formato de " $x$ " próximos aos primórdios dos cogumelos, e, com um auxilio de um spray de água, induzida a frutificação com uma pequena névoa de água sobre os cortes em um período de três vezes ao dia.

COLHEITA: Assim que os cogumelos começaram a liberar esporos foi realizada a colheita onde as amostras foram pesadas para calcular a eficiência biológica de cada substrato determinada pela relação entre cogumelo fresco e substrato seco conforme (BISARIA, 1987).

Peso do cogumelo fresco $(g)$

$E B(\%)=$ $\mathbf{X} 100$

Peso do substrato inicial $(g)$

Fontes et al (2017).

\section{RESULTADOS}

\subsection{RESULTADOS DO CRESCIMENTO MICELIAL IN VITRO}

Conforme mostra a tabela 1, podemos observar que os fungos conseguiram se desenvolver em todos os meios testados. 
Tabela 1: Crescimento micelial

\begin{tabular}{|l|l|l|l|}
\hline Meios de Cultivo & $\begin{array}{l}\text { Valor médio do halo } \\
\text { (mm/ } \mathbf{5} \text { dias)Pleurotus } \\
\text { Ostreatus }\end{array}$ & $\begin{array}{l}\text { Valor médio do } \\
\text { halo }\end{array}$ \\
& & (mm/ 5 dias) \\
\hline Meio Convencional & caju \\
\hline Bagaço de malte puro & 26,6 & 26,4 \\
\hline Meio com adição do bagaço de & 25,8 & 16,8 \\
\hline malte & 13,0 & 27,25 \\
\hline
\end{tabular}

Além da (TABELA 1) pode-se observar nos gráficos (1 - 14) o crescimento diário dos fungos. Fonte: Autor.

Gráfico 1: Avaliação do crescimento do fungo P.sajor-caju em Bagaço puro de malte, avaliado o raio em $\mathrm{mm} /$ dia durante 5 dias

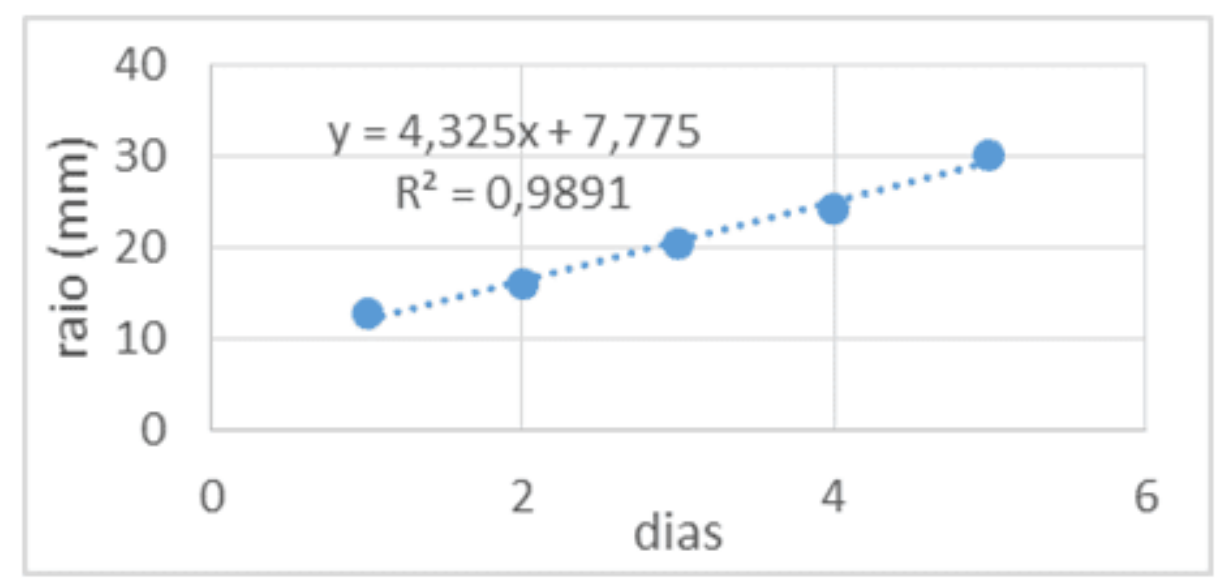

Fonte: $\mathrm{O}$ autor. 
Gráfico 2: Avaliação do crescimento do fungo P.sajor-caju em Bagaço puro de malte, avaliado o raio em $\mathrm{mm} /$ dia durante 5 dias

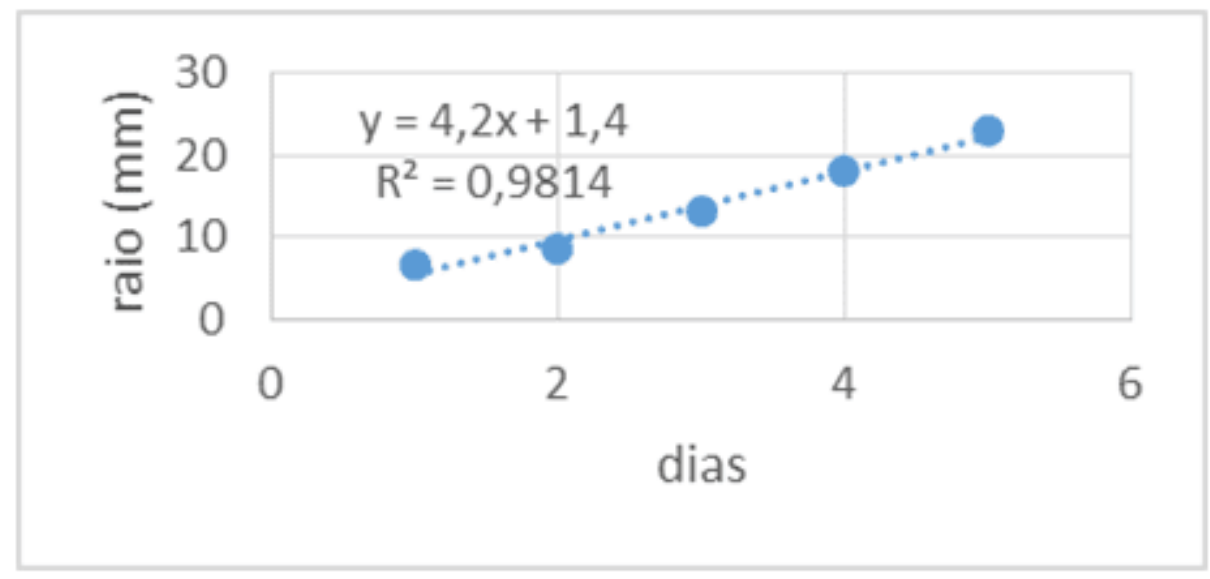

Fonte: $\mathrm{O}$ autor.

Gráfico 3: Avaliação do crescimento do fungo P.ostreatus em Bagaço puro de malte, avaliado o raio em $\mathrm{mm} /$ dia durante 5 dias

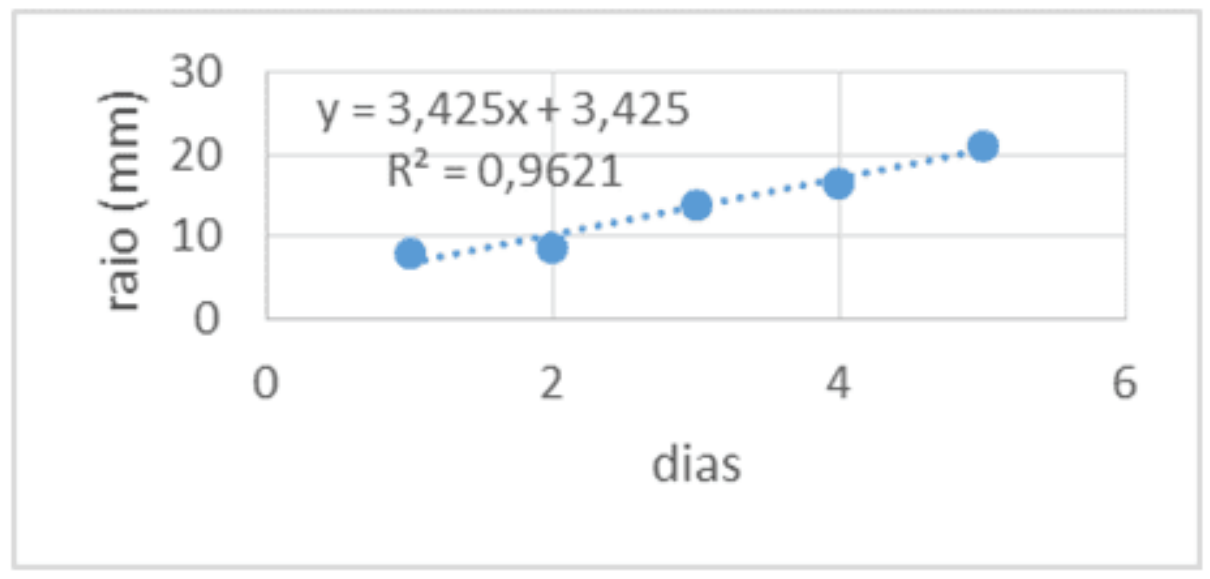

Fonte: $\mathrm{O}$ autor. 
Gráfico 4: Avaliação do crescimento do fungo P.ostreatus em Bagaço puro de malte, avaliado o raio em $\mathrm{mm} /$ dia durante 5 dias

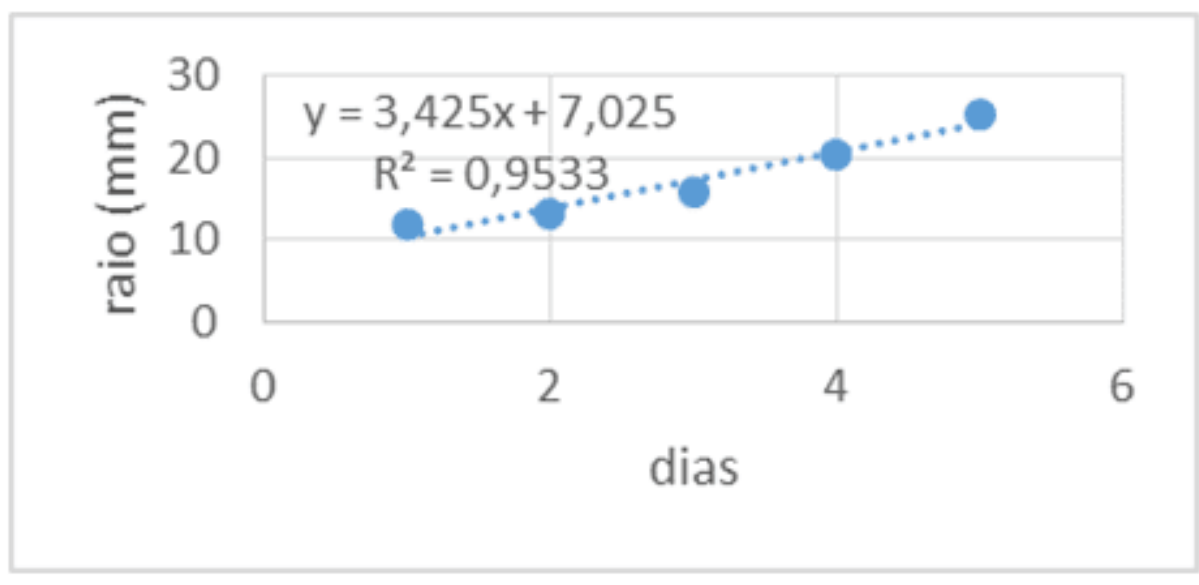

Fonte: $\mathrm{O}$ autor.

Gráfico 5: Avaliação do crescimento do fungo P.ostreatus em Bagaço puro de malte, avaliado o raio em $\mathrm{mm} /$ dia durante 5 dias

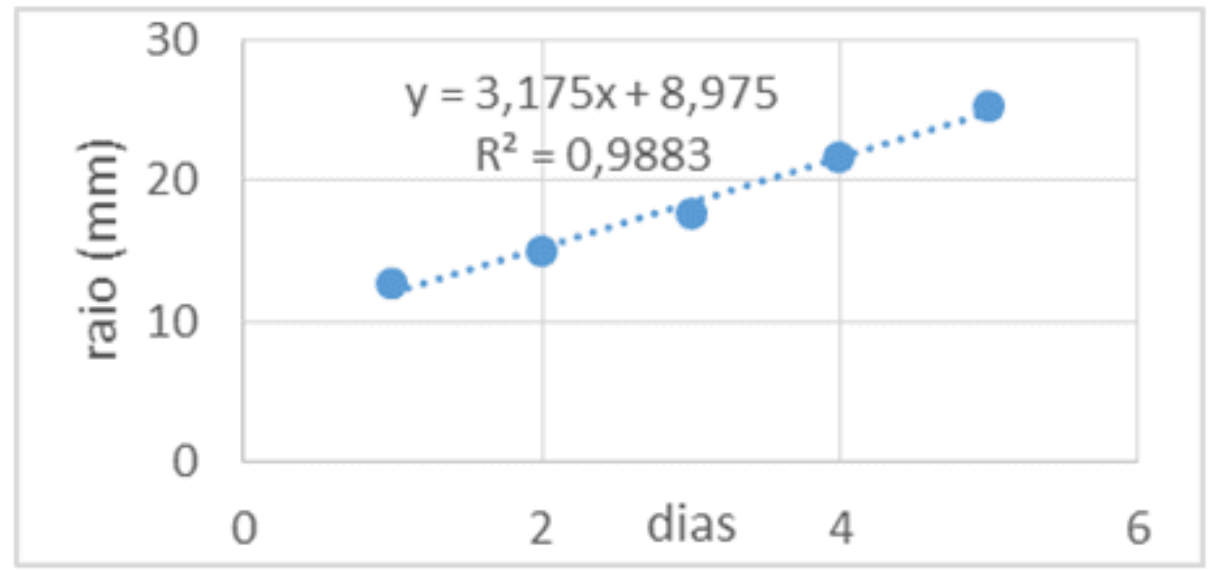

Fonte: $\mathrm{O}$ autor. 
Gráfico 6: Avaliação do crescimento do fungo P.sajor-caju em Meio convencional, avaliado o raio em $\mathrm{mm} /$ dia durante 5 dias

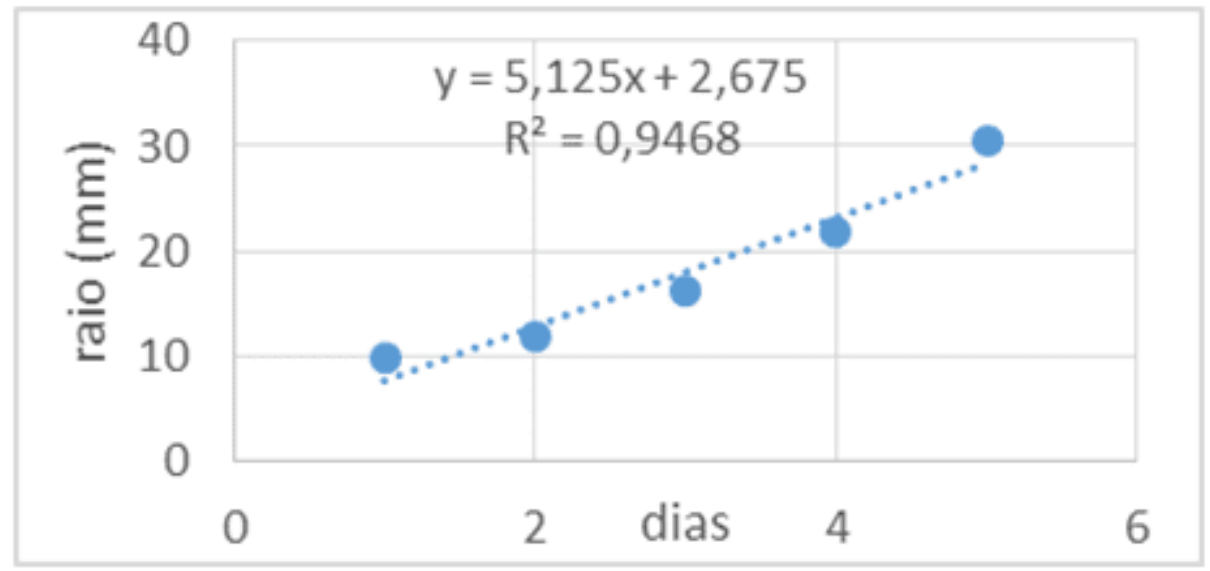

Fonte: $\mathrm{O}$ autor.

Gráfico 7: Avaliação do crescimento do fungo P.sajor-caju em Meio convencional, avaliado o raio em $\mathrm{mm} /$ dia durante 5 dias

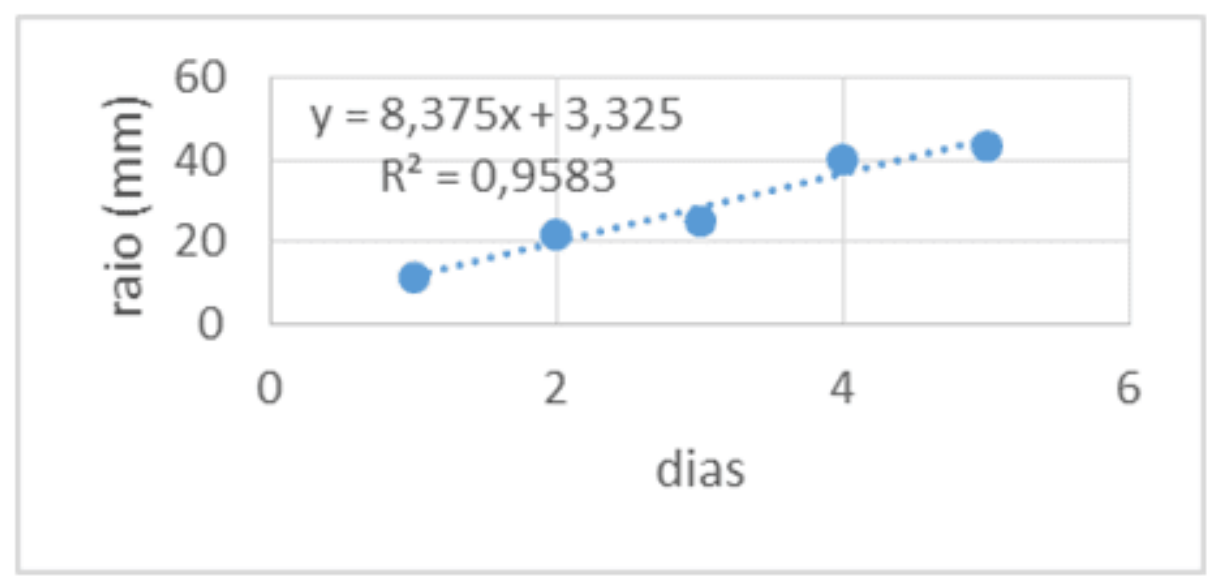

Fonte: $\mathrm{O}$ autor. 
Gráfico 8: Avaliação do crescimento do fungo P.sajor-caju em Meio convencional, avaliado o raio em $\mathrm{mm} /$ dia durante 5 dias

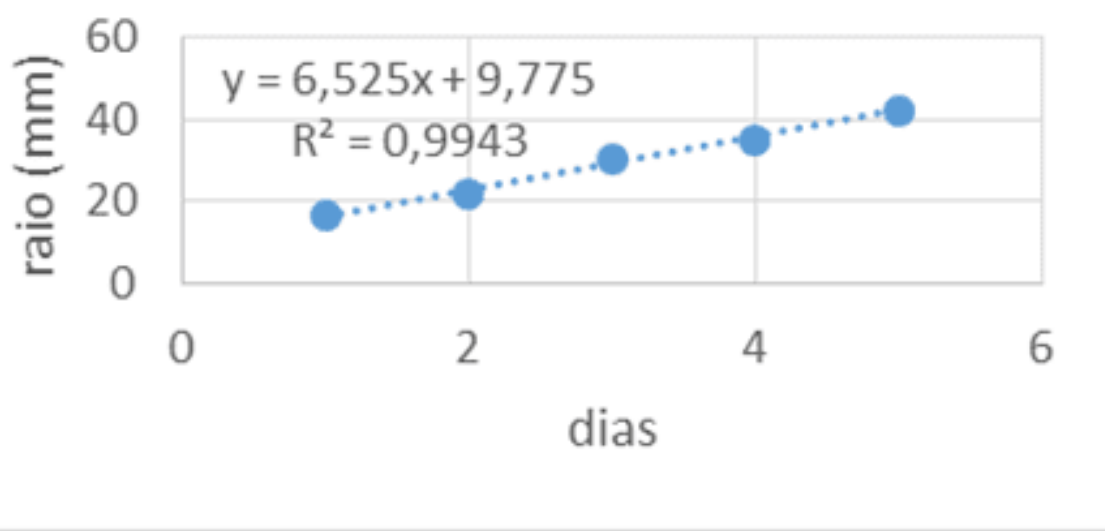

Fonte: $\mathrm{O}$ autor.

Gráfico 9: Avaliação do crescimento do fungo P.ostreatus em Meio convencional, avaliado o raio em $\mathrm{mm} /$ dia durante 5 dias

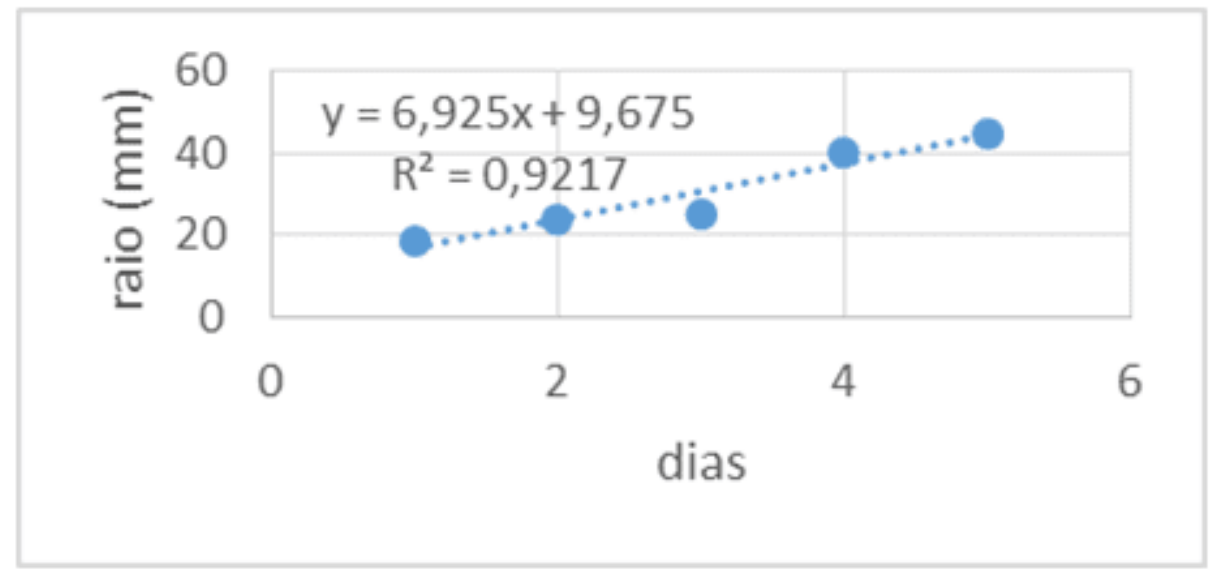

Fonte: $\mathrm{O}$ autor. 
Gráfico 10: Avaliação do crescimento do fungo P.ostreatus em Meio convencional, avaliado o raio em $\mathrm{mm} /$ dia durante 5 dias

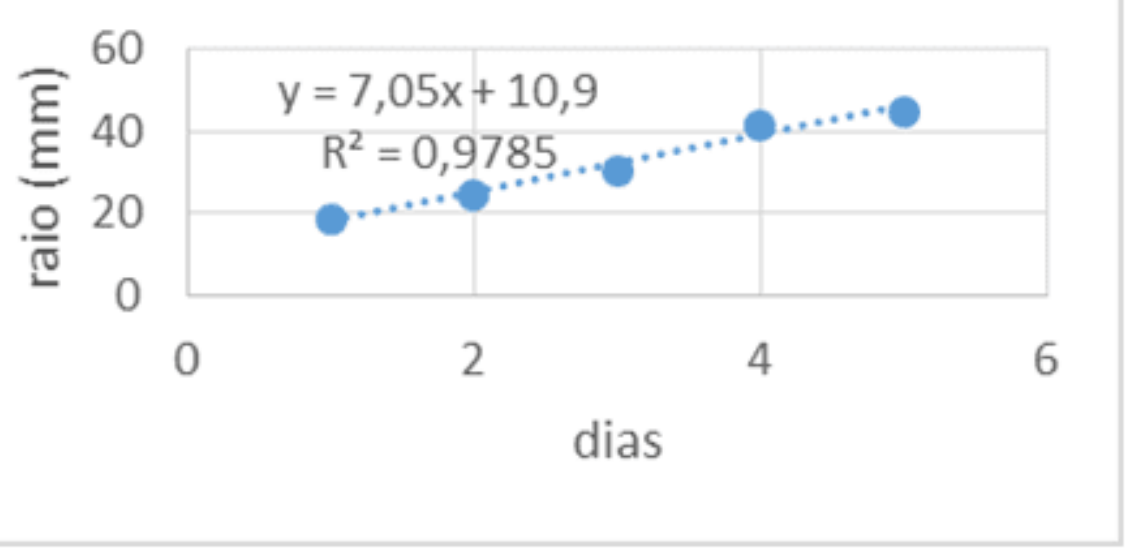

Fonte: $\mathrm{O}$ autor.

Gráfico 11: Avaliação do crescimento do fungo P.ostreatus em Meio com adição de bagaço de malte, avaliado o raio em $\mathrm{mm} /$ dia durante 5 dias

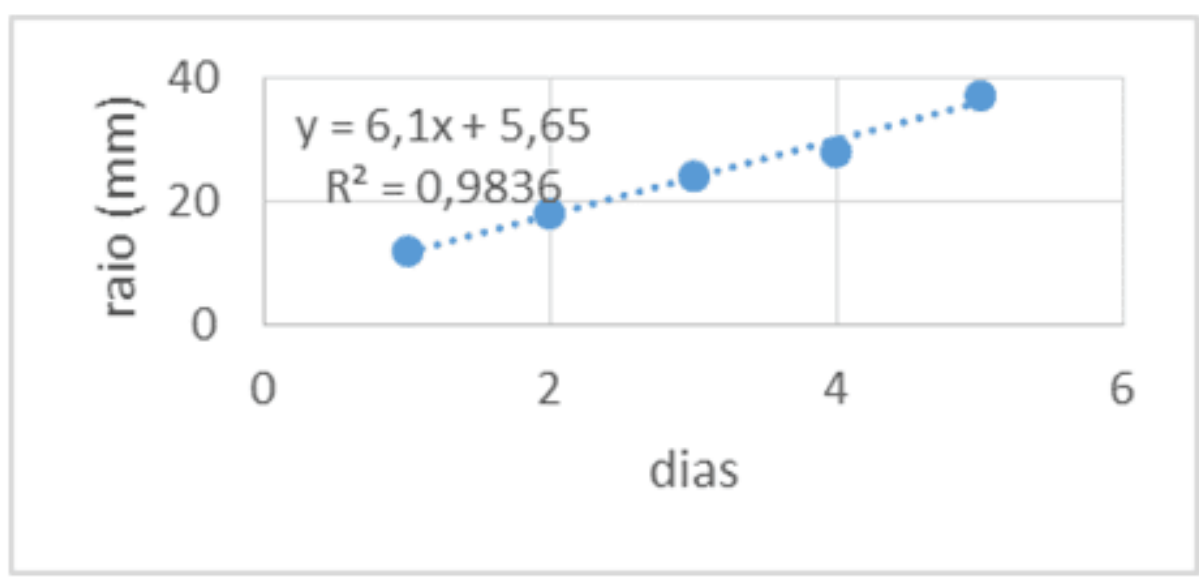

Fonte: $\mathrm{O}$ autor. 
Gráfico 12: Avaliação do crescimento do fungo P.ostreatus em Meio com adição de bagaço de malte, avaliado o raio em $\mathrm{mm} /$ dia durante 5 dias

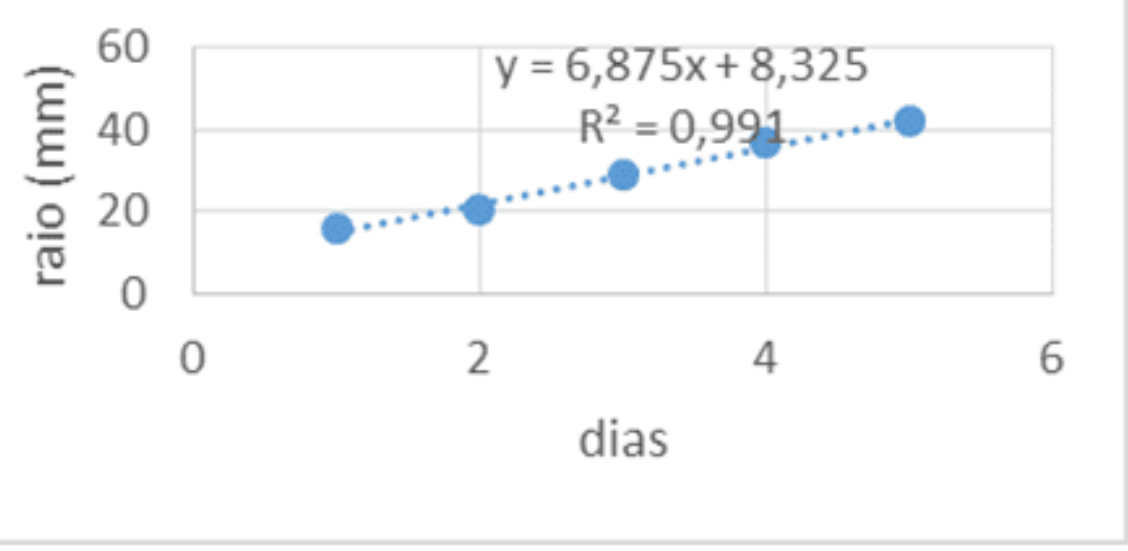

Fonte: $\mathrm{O}$ autor.

Gráfico 13: Avaliação do crescimento do fungo P.sajor-caju em Meio com adição de bagaço de malte, avaliado o raio em $\mathrm{mm} /$ dia durante 5 dias

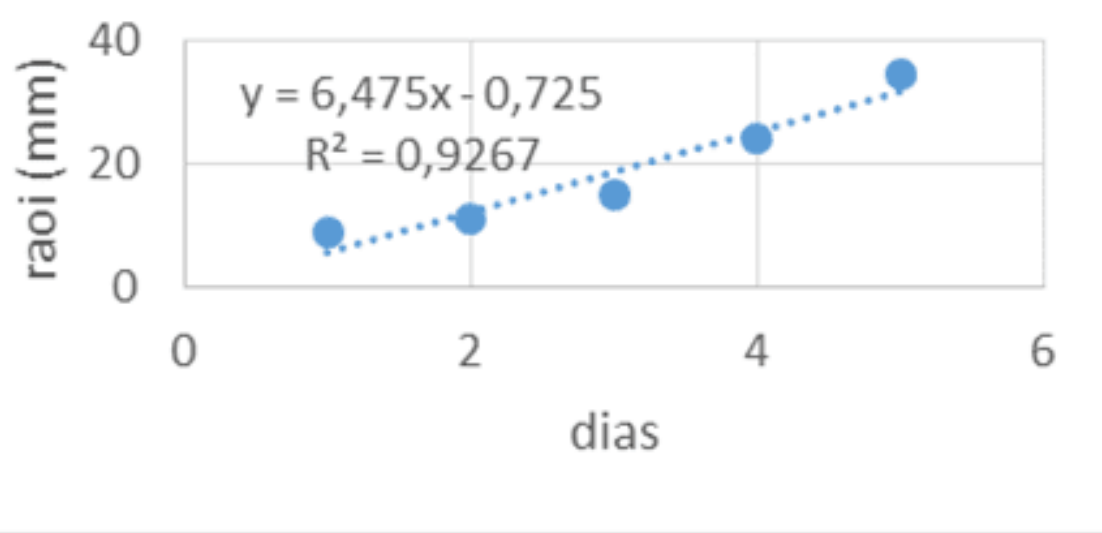

Fonte: $\mathrm{O}$ autor. 
Gráfico 14: Avaliação do crescimento do fungo P.sajor-caju em Meio com adição de bagaço de malte, avaliado o raio em $\mathrm{mm} /$ dia durante 5 dias

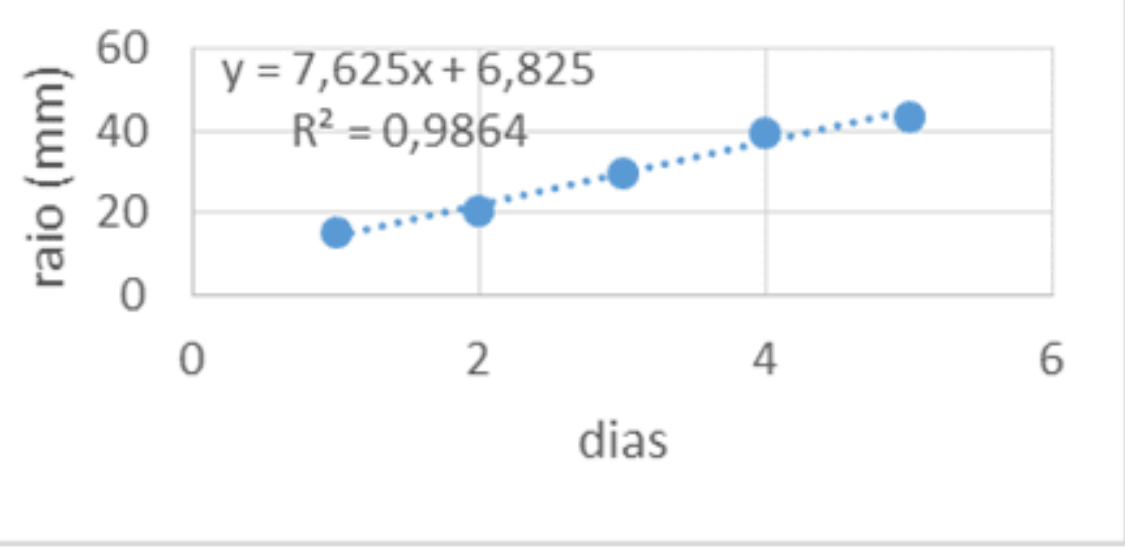

Fonte: $\mathrm{O}$ autor.

Gráfico 15: Média do crescimento micelial (MM) dia

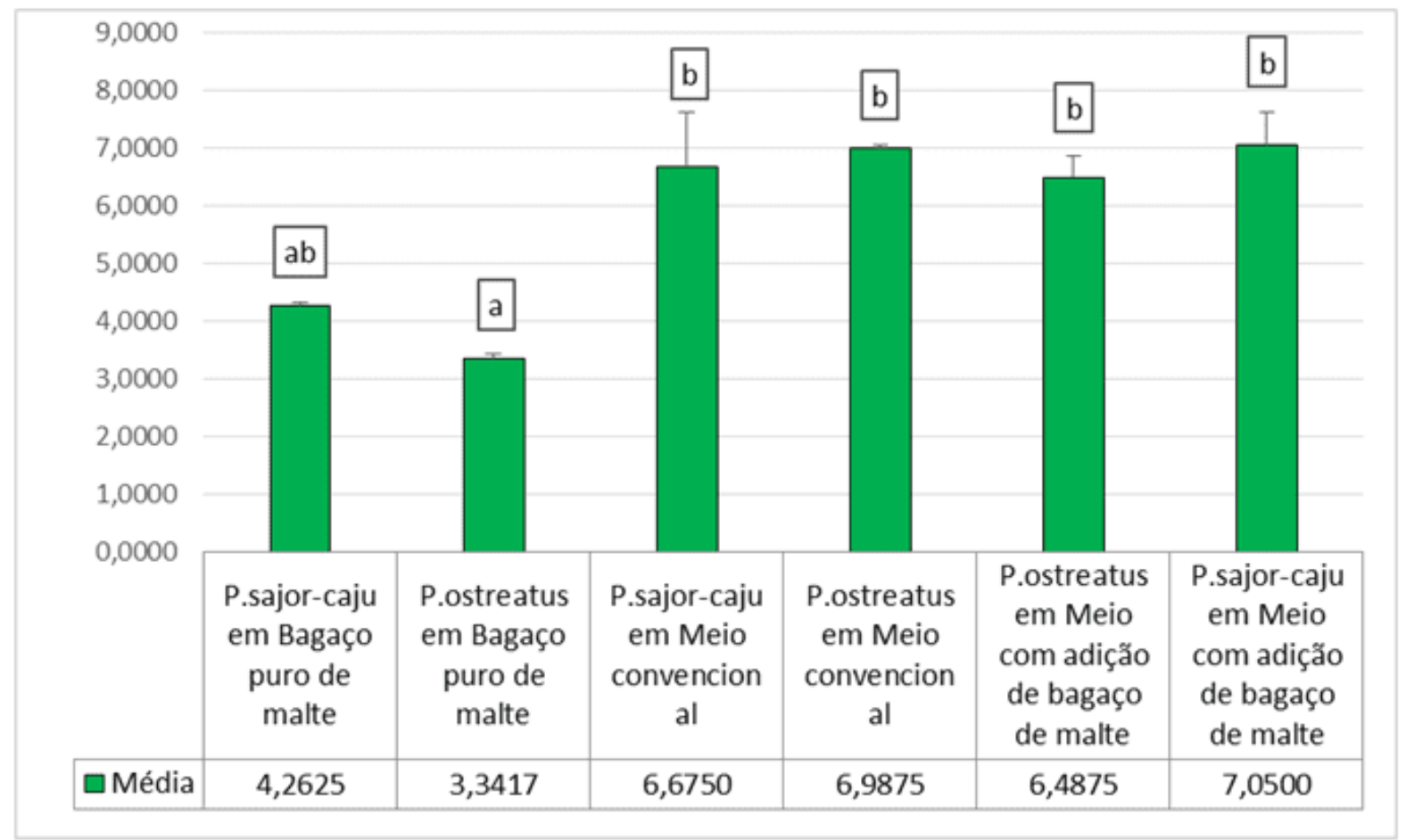

Fonte: $\mathrm{O}$ autor. 


\subsection{RESULTADOS DO VIGOR IN VITRO}

Um critério claramente observado nesse estudo foi a variação de vigor dos fungos diante de cada meio de cultivo (FIGURAS 4 e 5, 6 e 7, 8 e 9).

Figura 4: Fungo P.ostreatus em Meio convencional

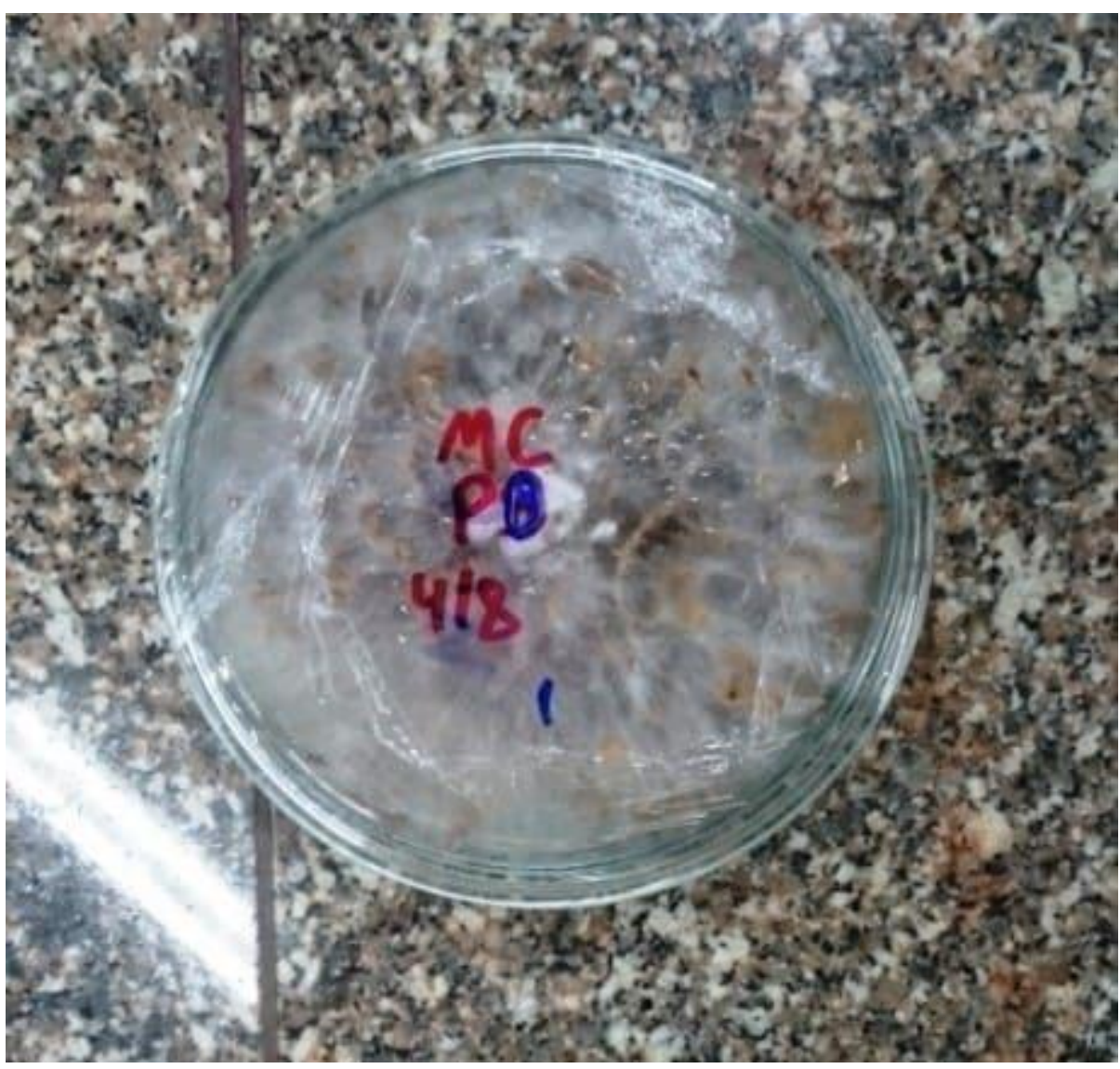

Fonte: $\mathrm{O}$ autor. 
Figura 5: Fungo P.sajor-caju em Meio convencional

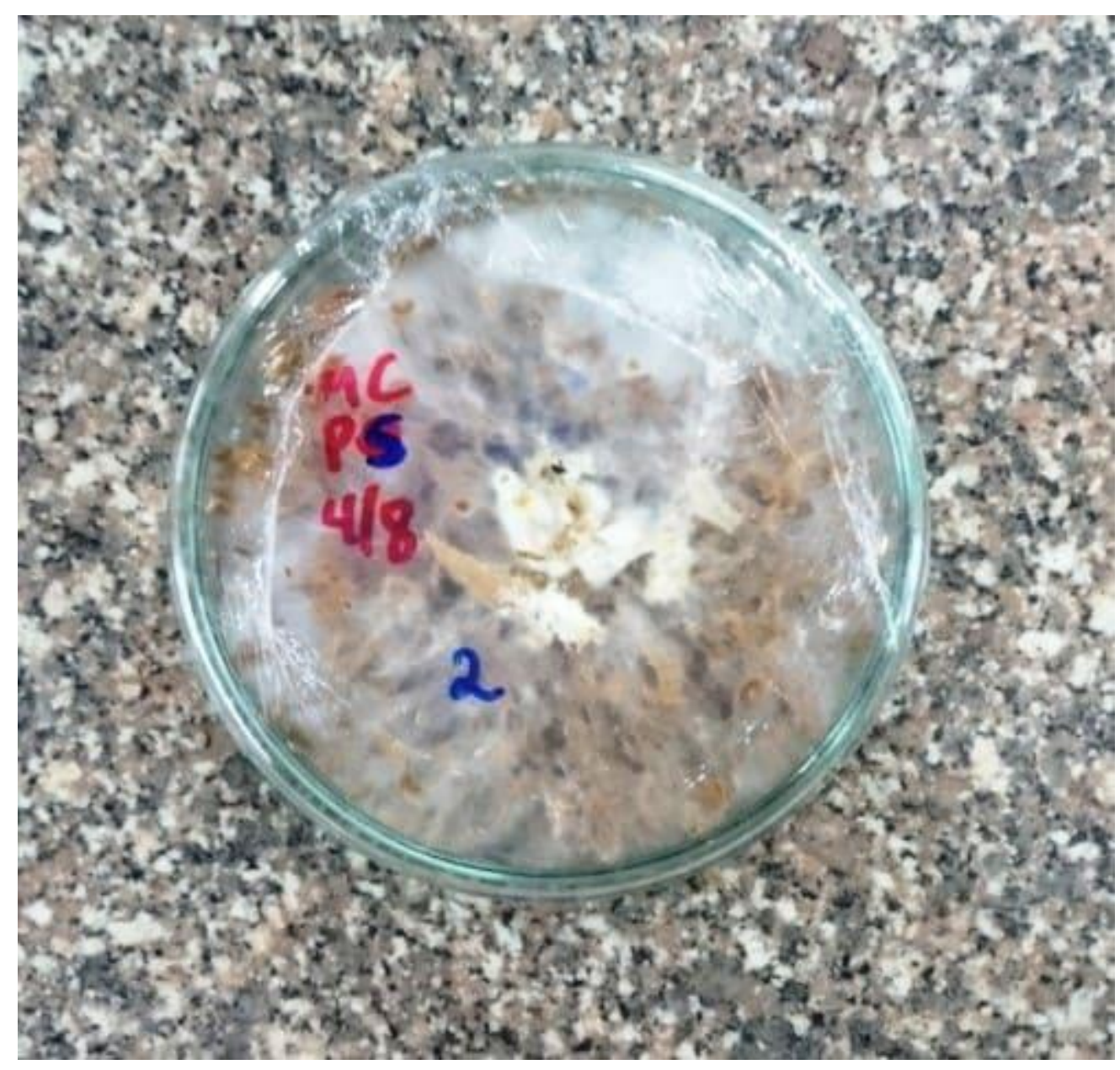

Fonte: $\mathrm{O}$ autor.

As duas espécies em meio convencional apresentaram uma variação entre pouco vigor a vigor intermediário. 
Figura 6: Fungo P.ostreatus em Bagaço puro de malte

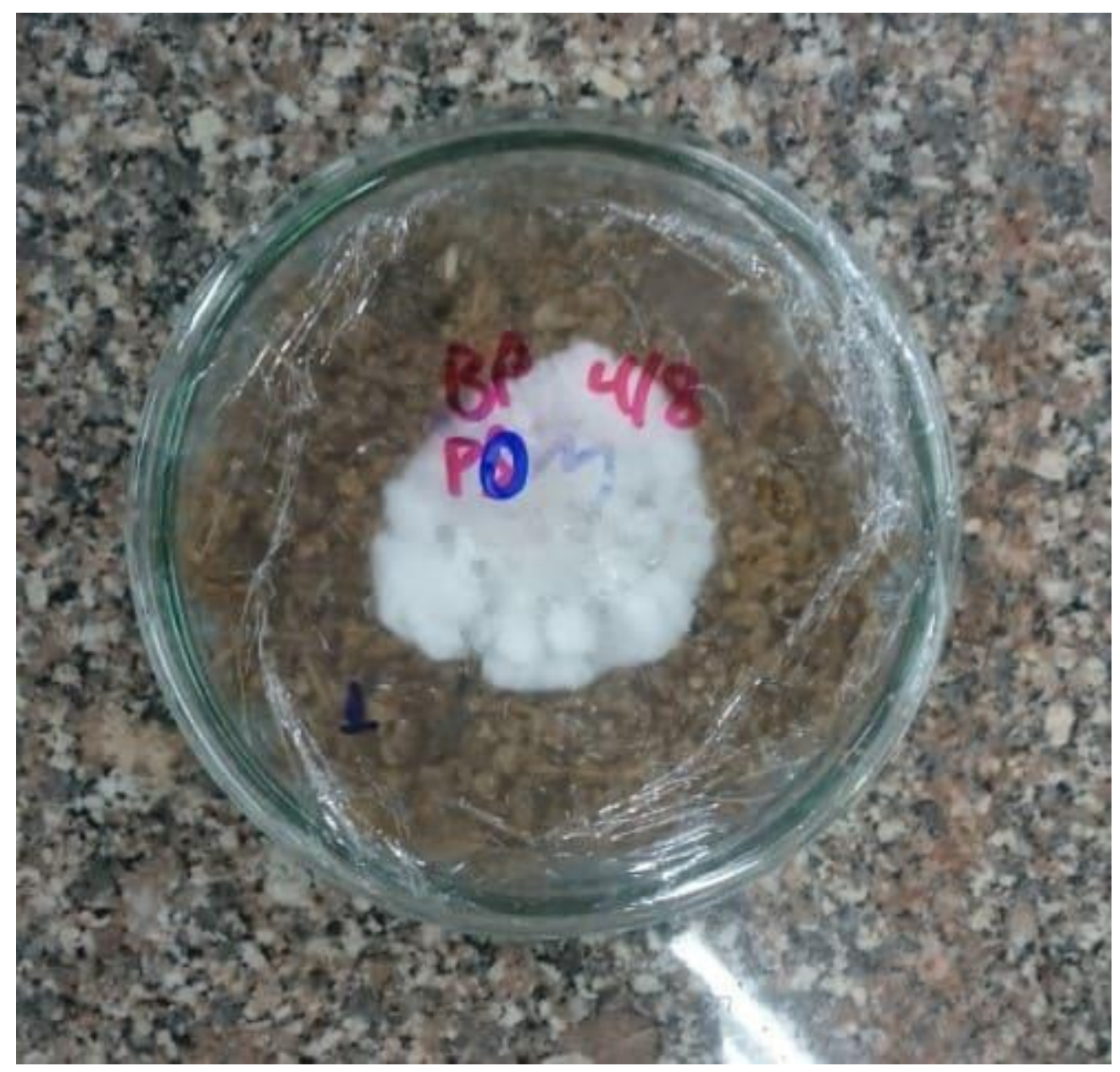

Fonte: $\mathrm{O}$ autor. 
Figura 7: P.sajor-caju em Bagaço puro de malte

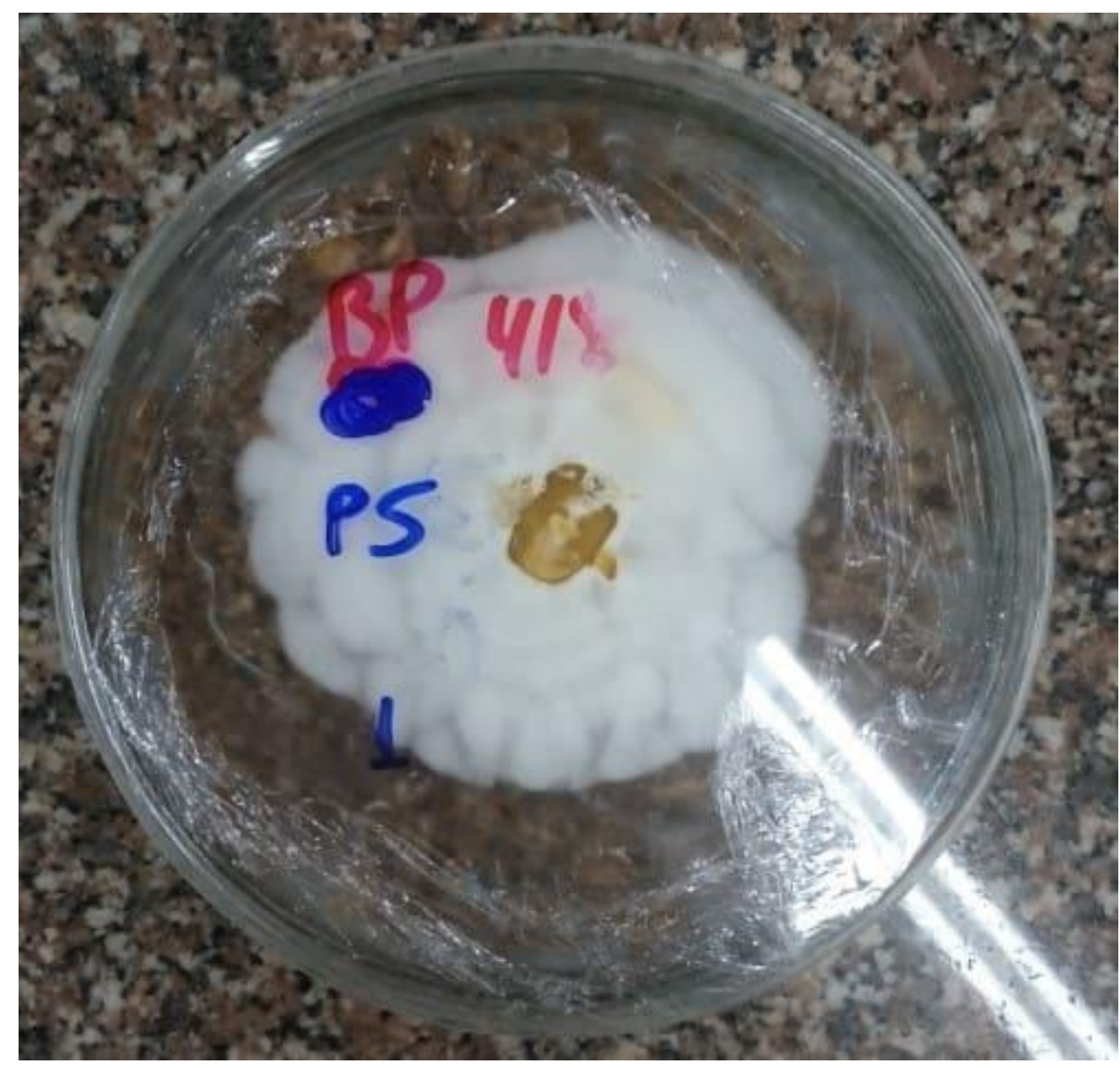

Fonte: $\mathrm{O}$ autor.

As mesmas espécies em bagaço de malte puro apresentaram muito vigor. 
Figura 8: P.ostreatus em Meio com adição de bagaço de malte

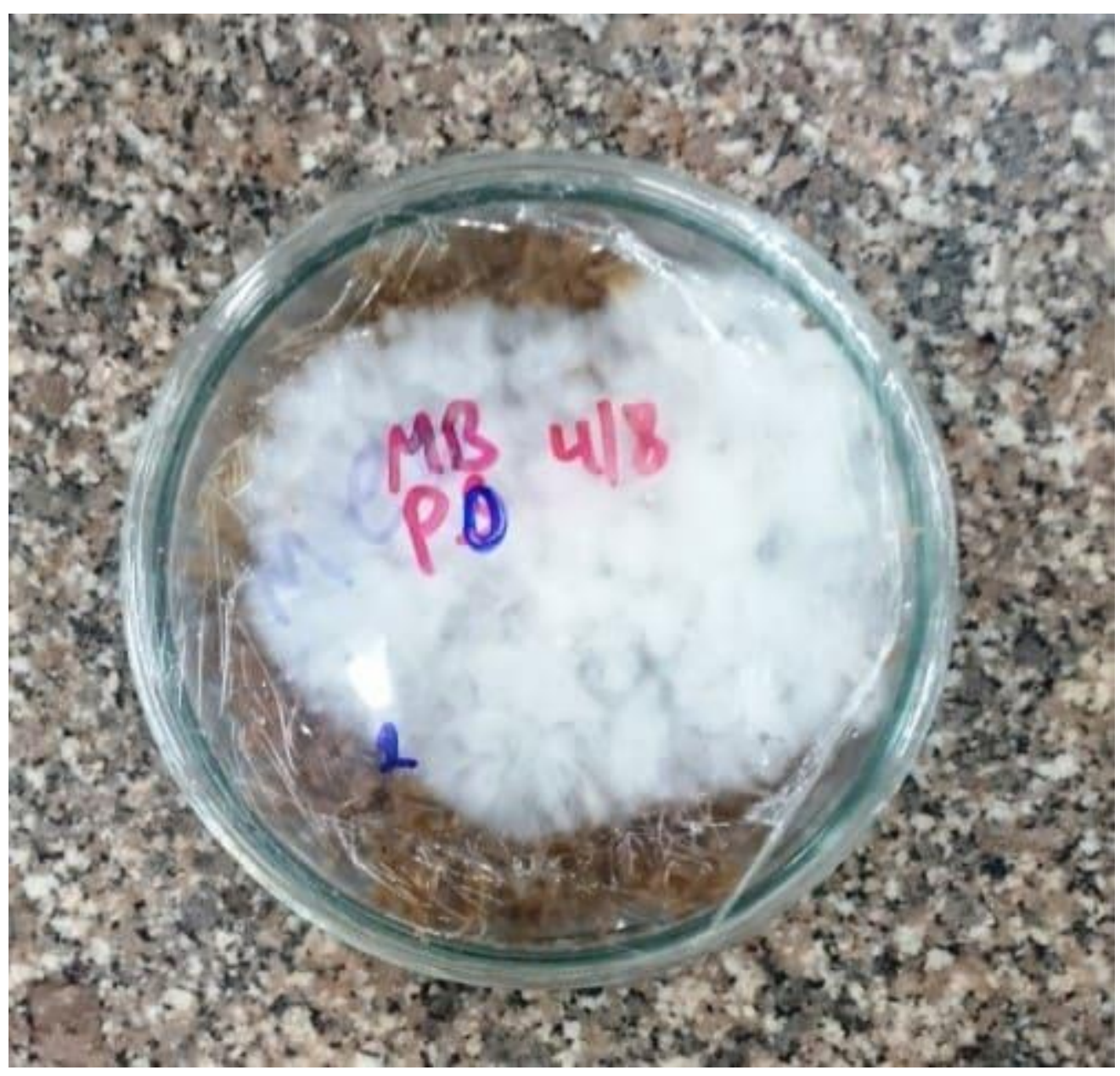

Fonte: $\mathrm{O}$ autor. 
Figura 9: P.sajor-caju em Meio com adição de bagaço de malte

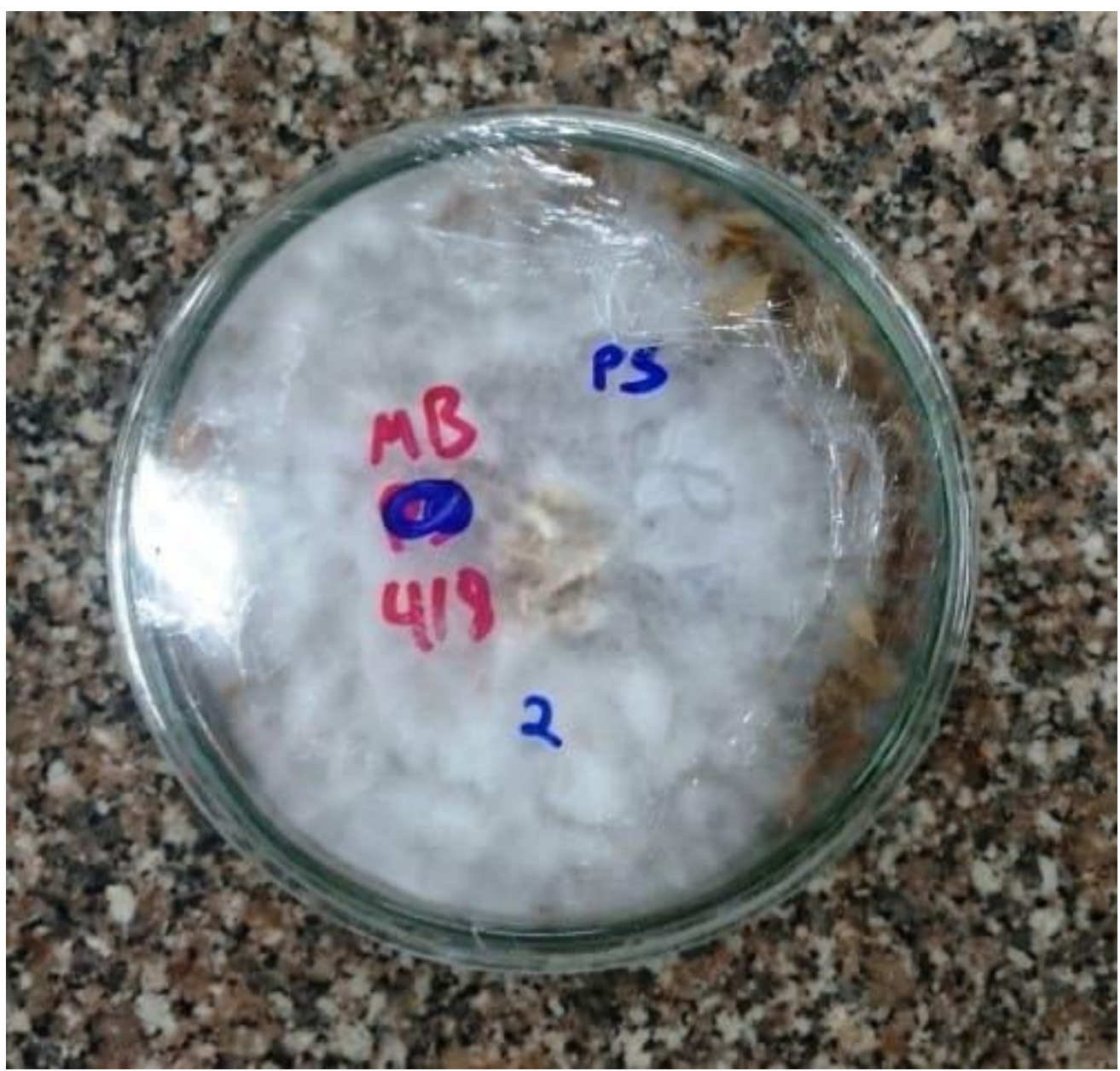

Fonte: $\mathrm{O}$ autor.

Em meio com adição de bagaço de malte as duas espécies apresentaram um vigor intermediário comparado aos dois meios citados anteriormente.

\subsection{RESULTADOS DA EFICIÊNCIA BIOLÓGICA DO CULTIVO AXÊNICO}

Os GRÁFICO 16 Mostra a comparação entre médias de eficiência biológica entre os sacos de cultivo utilizados no cultivo axênico. 
Gráfico 16: Eficiência Biológica

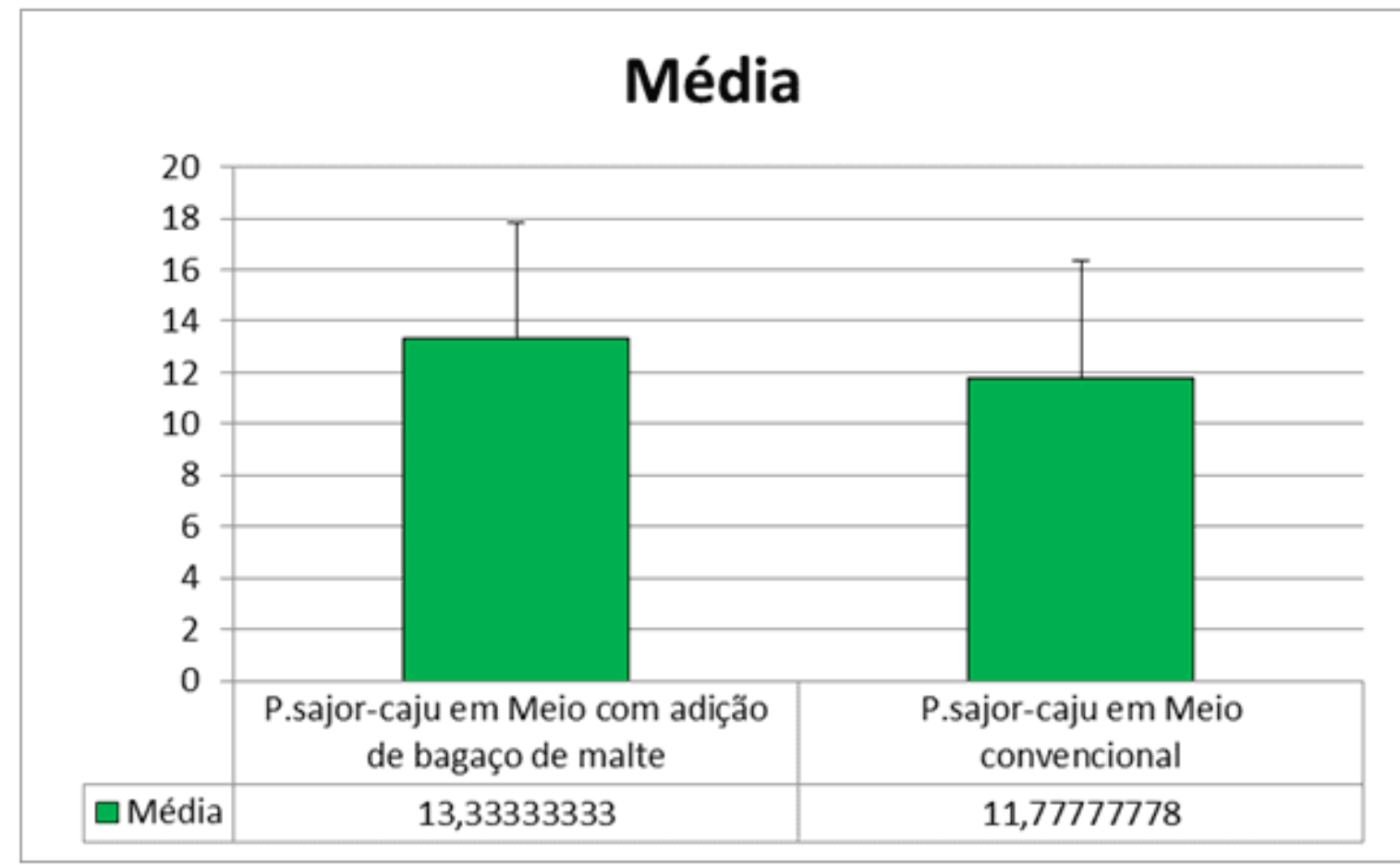

Fonte: $\mathrm{O}$ autor.

\section{DISCUSSÃO}

\subsection{CRESCIMENTO MICELIAL}

Todas as espécies ficaram mantidas na estufa incubadora na mesma temperatura, pois conforme BORTOLETO 2010, a temperatura pode influenciar no crescimento micelial. Tanto em meio convencional quanto em meio com adição de bagaço de malte foi possível observar um crescimento micelial rápido e maior, o que é justificado pelo fato de que esses dois meios tem o cepilho como base estrutural, possuindo uma maior circulação de ar. Já o meio composto somente por bagaço de malte apresenta um crescimento micelial menor, pois tem menor circulação de ar em seu interior, já que sua composição possui um material mais fino entre os três meios avaliados. De acordo com JONATHAN 2008, o crescimento rápido do fungo de interesse reduzira as chances de crescimento de outro micro-organismo competidor, reduzindo as chances de contaminação. 
Com relação as análises estatísticas Anova - Tukey, definiu-se que para grupos diferentes pode-se dizer que a diferença foi significativa para um nível de significância de 5\%. Denominando os grupos: P.sajor-caju em Meio convencional, P.ostreatus em Meio convencional, P.ostreatus em Meio com adição de bagaço de malte e P.sajorcaju em Meio com adição de bagaço de malte com a letra (b) e dizendo que entre esses grupos não existe uma diferença significante. E que o grupo P.ostreatus em Bagaço puro de malte denominado com a letra (a) sim apresenta uma diferença significante entre os outros. Já o grupo P.sajor-caju em Bagaço puro de malte está entre os grupos (a) e (b) sendo denominado de (ab) ficando mais próximo de se encaixar em qualquer um dos grupo.

\subsection{VIGOR}

A partir de uma avaliação visual, foi possível perceber que o meio de cultivo convencional apresentou um vigor menor entre os três meios testados, o meio com bagaço de malte puro apresentou um vigor maior entre todos meios.á o meio de cultivo que tem adição de bagaço de malte em sua composição apresentou um equilíbrio entre os dois citados anteriormente. Acredita-se que a causa dessa variação de vigor entre substratos se deve a diferença de estruturação entre os meios de cultivo, conforme OEI.; VAN NIEUWENHUIJZEN 2006, a combinação entre material grosso e fino acaba fornecendo uma melhor base para estruturação, algo que justifica o equilíbrio apresentado pelo meio com adição de bagaço de malte que tem em sua composição o cepilho que ajuda com a circulação de ar além do bagaço de malte, que é uma ótima fonte de nutrientes.

\subsection{CULTIVO AXÊNICO}

Com relação ao cultivo axênico, realizou-se em meio convencional e em meio com adição de bagaço de malte apenas com a espécie de fungo P.sajor-caju Singer pois foi a que se saiu melhor nos testes de crescimento micelial. Com relação aos resultados, podemos afirmar que nas condições apresentadas no trabalho o meio com adição de bagaço de malte apresentou uma eficiência biológica um pouco maior além de um desvio padrão um pouco menor que o meio convencional, reforçando a ideia 
de que o meio com adição de bagaço de malte mostra um equilíbrio maior que o meio convencional. Uma explicação para isso pode ser também a grande quantidade de nutrientes presente no bagaço de malte conforme STEFANELLO et al (2014). Quando comparamos nossos resultados encontrados com ALVES (2007) ou FONTES et al (2017) podemos observar que outras combinações de matéria prima ou outros subtrato e espécies de fungos tem a possibilidade de fornecer resultados diferentes de eficiência biológica, algo que pode contribuir para o desenvolvimento de novas idéias.

\section{CONCLUSÃO}

Pode-se concluir que o bagaço de malte pode ser utilizado para produção de cogumelos e que o meio de cultivo com adição de bagaço de malte é muito promissor, podendo fornecer resultados até melhores dependendo da espécie a ser cultivada, ambiente ou variações em sua própria composição.

Um desafio que pode ser utilizado pela Biotecnologia como tema de futuras pesquisas seria o de encontrar composições adequadas para determinadas espécies utilizando o bagaço do malte, alem de encontrar formas de transformar o resíduo da produção de cogumelos em um sub-produto assim como o trabalho fez com o bagaço de malte.

\section{REFERÊNCIAS}

ALVES, M., DONEGA, M., PERALTA, R. y Marques, C. Produção de inóculo do cogumelo comestível Pleurotus pulmonarius (Fr.) Quélet - CCB19 a partir de resíduos da agroindústria. Ciência e Tecnologia de Alimentos., 2007. Consulta: 18-denovembro de 2017. Disponível

em: http://www.redalyc.org/articulo.oa?id=395940085015.

BORTOLETO, MARINA, Influência da temperatura no crescimento micelial de linhagens de Lentinula edodes, Ambiência - Guarapuava (PR), v. v.6 n.3, p. p.503$509,2010$. 
CARDOSO, JÉSSICA CASAGRANDE POLEIS, Cultivo do cogumelo comestível Pleurotus osteatus em bagaço de bocaiuva e de cana-de-açúcar pela técnica junção, Evidência, v. 13 n. 1, p. 31-40, 2013.

ERENO, DINORAH., Esterilização Dinâmica, Revista Pesquisa Fapesp, v. 152, p. 80 83, 2008.

FAN, LEIFA.; SOCCOL, CARLOS RICARDO, Produção do cogumelo comestível Flammulina velutipes em casca e borra de café, Simpósio de Pesquisa dos Cafés do Brasil, p. 691-694, 2001.

FONTES, ARAILDE.;et al, Produção de Cogumelos por meio da Tecnologia Chinesa Modificada - Biotecnologia e aplicações na saúde, Editora Técnica,3ํeㄹição, p. 122124, 2017.

GOMES, LETÍCIA, "Cultivo de Lentinula edodes e Pleurotus ostreatus em bagaço de cana-de-açúcar, 58 páginas, Dissertação de Mestrado, Universidade Estadual Paulista, 2016.

INSTITUTO BRASILEIRO DE GEOGRAFIA E ESTATÍSTICA - IBGE, Indicadores IBGE estatística da produção agrícola, 2017. Disponível em: ftp://ftp.ibge.gov.br/Producao_Agricola/Levantamento_Sistematico_da_Producao_Ag ricola_[mensal]/Fasciculo/lspa_201701.pdf . acessado: 15/11/2017 ás 16:37

JONATHAN, S.G.; FASIDI, I.O.; AJAYI, A.O.; ADEGEYE, O. Biodegradation of Nigerian wood wastes by Pleurotus tuber-regium (Fries) Singer. Bioresource Technology, v.99, p.807-811, 2008.

MONAICO, EVELISE, Produção de Pleurotus sajor-caju em bagaço de cana-deaçúcar lavado e o uso de aditivos visando sua conservação "in natura", 84 páginas, Dissertação de Mestrado, Universidade de São Paulo, 2003. 
MUSSATTO, S. I.; DRAGONE, G.; ROBERTO, I. C. BREWERS' SPENT GRAIN, Generation, characteristics and potential applications, Journal of Cereal Science. v. 43, p 1-14, 2006.

OEI, PETER.; VAN NIEUWENHUIJZEN, BRAM, O Cultivo de cogumelos em pequena escala, v. 40 Agromisa p. 13-39 - 2006.

STEFANELLO, FLÁVIA ET AL., Resíduo de cervejaria: Bioatividade dos compostos fenólicos; aplicabilidade na nutrição animal e em alimentos funcionais, REGET UFSM - Santa Maria, v. 18, p. 3, 2014.

Enviado: Agosto, 2018.

Aprovado: Julho, 2019. 